\title{
Comparison of Air Pollutants' Hazardous Levels in Selected Cities of Malaysia: Entropy Method
}

\author{
Nur Syamimi Muhamad Fauzi ${ }^{1, *}$, Maznah Mat Kasim¹, Nor Hasliza Mat Desa ${ }^{2}$ \\ ${ }^{1}$ Department of Decision Science, School of Quantitative Sciences, Universiti Utara Malaysia, 06010 UUM Sintok, Kedah, Malaysia \\ ${ }^{2}$ Department of Statistics, School of Quantitative Sciences, Universiti Utara Malaysia, 06010 UUM Sintok, Kedah, Malaysia
}

Received November 18, 2020; Revised May 31, 2021; Accepted July 8, 2021

\begin{abstract}
Cite This Paper in the following Citation Styles
(a): [1] Nur Syamimi Muhamad Fauzi, Maznah Mat Kasim, Nor Hasliza Mat Desa, "Comparison of Air Pollutants' Hazardous Levels in Selected Cities of Malaysia: Entropy Method," Universal Journal of Public Health, Vol. 9, No. 4, pp. 194 - 200, 2021. DOI: 10.13189/ujph.2021.090405.
\end{abstract}

(b): Nur Syamimi Muhamad Fauzi, Maznah Mat Kasim, Nor Hasliza Mat Desa (2021). Comparison of Air Pollutants' Hazardous Levels in Selected Cities of Malaysia: Entropy Method. Universal Journal of Public Health, 9(4), 194 - 200. DOI: 10.13189/ujph.2021.090405.

Copyright $\bigcirc 2021$ by authors, all rights reserved. Authors agree that this article remains permanently open access under the terms of the Creative Commons Attribution License 4.0 International License

\begin{abstract}
The ambient of air quality in Malaysia is described in terms of Air Pollutant Index (API) which is calculated based on the maximum value of sub-index values of each of the six air pollutants (Sulphur Dioxide $\left(\mathrm{SO}_{2}\right)$, Nitrogen Dioxide $\left(\mathrm{NO}_{2}\right)$, Carbon Monoxide $(\mathrm{CO})$, Ozone $\left(\mathrm{O}_{3}\right)$, particulate matter with aerodynamic diameter less than 10 micrometres $\left(P M_{10}\right)$ and particulate matter with aerodynamic diameter less than 2.5 micrometres $\left(P M_{2.5}\right)$. It is argued that the existing API cannot give the true picture of how harmful the pollution is towards humans' health because the hazardous levels of these pollutants are not considered in the API development. Therefore, the aim of this study is to determine the weights of the air pollutants according to their levels of hazardous in three selected cities in Malaysia; Putrajaya (PJ), Tawau (TW) and Alor Setar (AS). The study applies Shannon entropy method to weigh the air pollutants where the entropy values of the pollutants are the proxy measure of the pollutants' weights. The pollutants with higher weights would contribute more to air pollution and vice-versa. The study found different weights of the pollutants according to different cities where PJ shows $\mathrm{SO}_{2}$ at the top ranking with $48.16 \%$ of the air pollutants' weight. Meanwhile, TW and AS show $P M_{2.5}$ at the first rank with $36.31 \%$ and $31.79 \%$ respectively. However, the analysis on the overall data shows that $P M_{2.5}$ and $P M_{10}$ are at the most and second most hazardous pollutants respectively that contribute to the air pollution. The effect of these two particulate matters is said to be more serious since $\mathrm{SO}_{2}$ that is
\end{abstract}

associated with both particulate matters are difficult to breakdown and bring harmful effects in human life as compared to the other air pollutants. This study signifies a new perspective in measuring the hazardous levels of the air pollutants and the results could be used to improve the existing API in monitoring the air quality in Malaysia.

Keywords Air Pollutants, Level of Hazardous, Weightage, Objective Weight, Entropy Method

\section{Introduction}

Pollution or environmental pollution defines the addition of contaminants into the natural environment that causes reverse change. Pollution occurs when pollutants contaminate with the natural surrounding where the pollution can affect the changes of lifestyle adversely. Millions of people around the world are suffering from the impacts of air pollution from then until now. Historically, in 1952, a large cloud of sulphate aerosols covered London for just two days, yet killed about 12000 people[2]; Xi'an China recorded a total of 7965 cases of respiratory mortality; and India contributed $26.2 \%$ to the global air pollution disability-adjusted life-years (DALYs) in 2017[4]. By the year 2025, Malaysia will be heading to become an industrialized country. It is expected that during that time, a lot of factories development and enlargement will be taken place to satisfy the investors. This will bring a 
good impact to Malaysian economy but on the other hand, this development also will contribute harmful effects to our environment due to air pollution. Hence, the air quality in Malaysia is really a major concern. The unhealthy air pollution in Malaysia is really a big concern to Malaysians resulting in widespread of illness especially respiratory disease. Air pollution has been linked to respiratory diseases, higher rates of cancer, heart disease, and stroke[7] Ambient air pollution is made up of fine particulate matters while household air pollution is the use of kerosene and solid fuels where women and children have a higher tendency to risk of household air pollution[8]. Malaysians' health is threatened by polluted air due to increased urbanization, based on results of a study that relied on data on daily hospitalizations for cardiovascular and respiratory disorders, as well as data on air pollutants.

The ambient air quality measurement in Malaysia is described in terms of Air Pollutant Index (API) which was adopted in 1996. Previously, the Department of Environment (DOE) of Malaysia introduced Recommended Malaysian Air Quality Guidelines (RMG) in 1989, while in 1993, Malaysian Air Quality Index (MAQI) was established to ambient air quality status ranging from good to hazardous [10]. Also, based on the API readings, the public can easily be familiar with the air-quality status for determining their own health precautions and being informed about how clean or polluted the atmosphere is. Basically, the Malaysia API for a given period of time is the maximum value of the sub-index values of five pollutants namely Sulphur Dioxide $\left(\mathrm{SO}_{2}\right)$, Nitrogen Dioxide $\left(\mathrm{NO}_{2}\right)$, Carbon Monoxide $(\mathrm{CO})$, Ozone $\left(\mathrm{O}_{3}\right)$, and particulate matter with aerodynamic diameter less than 10 micrometre $\left(P M_{10}\right)$. The average concentration of each pollutant over a given period is then standardized using a specific mathematical formula to produce a non-unitary value called sub-index. DOE of Malaysia has improved the calculation of the API in August 2018, by including the particulate matter with aerodynamic diameter less than 2.5 micrometre $\left(P M_{2.5}\right)$ due to health impact of this fine particles that can lodge deeply in the lungs. The DOE used a single strand of human hair to illustrate the relative size of $P M_{10}$ and $P M_{2.5}[10]$.

However, the current calculation of the API in Malaysia only considered the maximum average of each pollutant. According to the DOE of Malaysia, they considered all the air pollutants are having the same effects to the human health[11]. Alyousifi et al. [12] also predicted the daily API but used the fuzzy time series (FTS) to develop an accuracy model for air pollution. Although fuzzy time series (FTS) is used to predict air pollution, it has limitations due to the utilization of an arbitrary number of intervals and also does not represent the hazardous level of each air pollutant. It is argued that the existing API cannot tell how serious that the air pollution could affect our health. Thus, the implementation of multi-criteria decision making (MCDM) methods in the calculation of API is appropriate to review the different effects that these pollutants bring to humans' lives. This is due to the facts that the MCDM used criteria weights in their aggregation [13] or in constructing the index. The purpose of weighting method is to indicate the relative importance of criteria in MCDM problems[14]. This study looks at this matter by using data driven-based method namely entropy method $[15,16]$ to measure the pollutants' levels of hazardous that may lead to a more accurate API reading.

The criteria of weights have carried an important role in measuring overall preference values of the alternative on some permissible scale in various MCDM models [14]. Some of the interpretation of criteria weights are marginal contribution per unit, relative contribution of average criterion, relative functional importance of the criteria and relative information content carried in the criteria. Thus, this study aimed to determine the weights of the air pollutants objectively according to their levels of hazardous by using the entropy method. Hence, in this study, the objective weights of pollutants represent the relative importance of the pollutants towards API which will indicate the level of their hazardous towards the human health in particular. The objective weight is determined based on intrinsic information contained in the criteria in the performance matrix or decision matrix [17]. Then, the weight of each air pollutant was determined according to its level of hazardous based on entropy measures of the pollutants. To achieve the main objective of this study, a descriptive analysis and the determination of objective weight must be done. The next section describes the data and the study area and the entropy method used to analyze the data. Then it is followed by results, discussion, and conclusion of the study.

\section{Methodology}

\subsection{Study Area and Data Collection}

The focus of this study is on determining the weights of each of the six air pollutants namely Sulphur Dioxide $\left(\mathrm{SO}_{2}\right)$, Nitrogen Dioxide $\left(\mathrm{NO}_{2}\right)$, Carbon Monoxide $(\mathrm{CO})$, Ozone $\left(\mathrm{O}_{3}\right)$, particulate matter with aerodynamic diameter less than 10 micrometre $\left(P M_{10}\right)$ and particulate matter with aerodynamic diameter less than 2.5 micrometre $\left(P M_{2.5}\right)$. Secondary data is used in this study which is the set of data from the DOE of Malaysia. The data used in this study was collected from the Air Quality Division of the DOE of Malaysia for year 2018 within three cities which are Putrajaya (PJ), Alor Setar (AS) and Tawau (TW). The decision of the selection of the cities is due to the report by IQAir [18]stated that Putrajaya is the most polluted city meanwhile Tawau is the cleanest city in Malaysia. Besides, PJ is one main urban city in Malaysia with heavy industrial activities and heavy traffics. Undeniably, these events produced urban air pollution that impacts the public health through the emission of potential 
hazardous pollutants into the air. Besides, this selection of cities is aimed to examine which air pollutant that contributes the most to the air pollution in the selected cities. The year selection is due to the improvement of the API calculation made by DOE in 2018 with the consideration of $P M_{2.5}$ in the calculation of API. The time interval for the air quality data collected is per day for 365 days.

\subsection{Objective Weighting Method}

In this study, objective weighting method is used to obtain the weight of each pollutant. The objective weight is based on intrinsic information of the data and it involves some of mathematical computations without any consideration of decision maker's opinion. One of the objective weight methods is the entropy method, where this entropy method can be used to measure the weight of each criterion. This method is based on the measure of uncertainty of the information or the entropy measures of the pollutants as formulated in probability theory. In other words, entropy is synonym to uncertainty. Basically, this study used the basic Shannon entropy method. The determination of objective weight using Shannon entropy usually involves five step processes as shown in Figure 1.

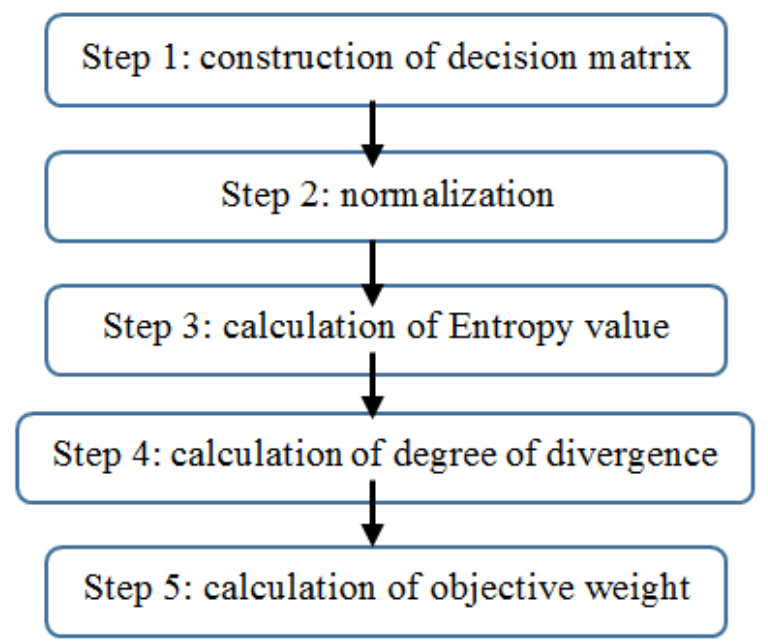

Figure 1. Summary of obtaining objective weight

$$
X=\begin{array}{cccc}
P_{1} & P_{2} & \ldots & P_{n} \\
A_{1} \\
A_{2} \\
\cdots \\
A_{m}
\end{array}\left[\begin{array}{cccc}
x_{11} & x_{12} & \ldots & x_{1 n} \\
x_{21} & x_{22} & \ldots & x_{2 n} \\
\ldots & \cdots & \ldots & \ldots \\
x_{m 1} & x_{m 2} & \ldots & x_{m n}
\end{array}\right]
$$

Figure 2. An example of a decision matrix

First step: Construction of decision matrix

The first step is the construction of decision matrix with $m$ alternatives or days, $A_{i}(i=1,2,3, \ldots, m)$ against $n$ criteria of air pollutants, $P_{j}(j=1,2,3, \ldots, n)$ and $x_{i j}$ is the daily reading of air pollutant for day $i$ with respect to $j$ th type of pollutant. A decision matrix can be briefly expressed in a matrix as shown in Figure 2.

In this study, $m$ is 365 , and $n$ is six since there are six pollutants under study for a one-year (2018) daily readings.

\section{Second step: Normalization}

Second, a normalization technique was used to transform the various criteria scale into a comparable scale. Then following equation of normalized score, $r_{i j}$ is computed as follows.

$$
r_{i j}=\frac{x_{i j}-x_{\min }}{x_{\max }-x_{\min }}
$$

where the $x_{\max }$ and $x_{\min }$ represent maximum and minimum frequency for each pollutant, respectively. The range of $r_{i j}$ is between zero and one.

\begin{tabular}{|c|c|c|}
\hline Pollutant & City & $\mathrm{Ej}$ \\
\hline \multirow{3}{*}{$\mathrm{PM}_{10}$} & TW & 0.990594 \\
\hline & AS & 0.980865 \\
\hline & PJ & 0.987777 \\
\hline \multirow{3}{*}{$\mathrm{PM}_{2.5}$} & TW & 0.985497 \\
\hline & AS & 0.9736 \\
\hline & PJ & 0.989407 \\
\hline \multirow{3}{*}{$\mathrm{SO}_{2}$} & TW & 0.997578 \\
\hline & AS & 0.985911 \\
\hline & PJ & 0.96024 \\
\hline \multirow{3}{*}{$\mathrm{NO}_{2}$} & TW & 0.994119 \\
\hline & AS & 0.991286 \\
\hline & PJ & 0.991803 \\
\hline \multirow{3}{*}{$\mathrm{O}_{3}$} & TW & 0.99494 \\
\hline & AS & 0.990379 \\
\hline & PJ & 0.992262 \\
\hline \multirow{3}{*}{$\mathrm{CO}$} & TW & 0.997327 \\
\hline & AS & 0.994917 \\
\hline & PJ & 0.99596 \\
\hline
\end{tabular}

Table 1. Entropy values of the three cities

Third step: Calculation of entropy value

Next, the third step is the entropy values $E_{j}$ are defined in Equation 2 as follows and the result of entropy values is shown in Table 1.

$$
E_{j}=-\frac{\left(\sum_{i=1}^{m} p_{i j} \ln \left(p_{i j}\right)\right)}{\ln (m)}
$$

where $p_{i j}=\frac{x_{i j}}{\sum_{i=1}^{m} x_{i j}}, p_{i j}$ is value of proportion of criteria $\mathrm{j}$ related to $\mathrm{i}$ where $i=1, \ldots, m$; and $j=1, \ldots, n$.

Fourth step: Calculation of degree of divergence 
Fourth, the degree of divergence $d_{j}$ of the intrinsic information in each pollutant's criterion is calculated as $d_{j}=1-E_{j}$ where the values of $d_{j}$ represent the inherent contrast of intensity of $j$ th criterion.

Fifth step: Calculation of objective weight

Thus, the last step of determination of objective weight for each criterion or each pollutant was calculated as shown in Equation 3.

$$
\begin{gathered}
w_{j}^{o b j}=\frac{1-E_{j}}{\sum_{j=1}^{n}\left(1-E_{j}\right)}, \quad j=1,2, \ldots, n \\
0 \leq \sum_{j=1}^{n} w_{j}{ }^{o b j} \leq 1 .
\end{gathered}
$$

\section{Results}

The data involved in this study is the 2018 data set, where the $P M_{2.5}$ is newly included into the calculation of the API due to this fine particles that can affect human health especially the respiratory disease. As mentioned in methodology part, this study involved three cities. Table 2 summarizes the descriptive statistics of the three cities on daily concentration of six air pollutants over 365 days. Based on Table 2, Putrajaya (PJ) has the highest mean value for almost all pollutants except for Carbon Monoxide (CO). PJ have the highest mean value and standard deviation for $P M_{10}, P M_{2.5}, S_{2}, N_{2}$ and $O_{3}$ which are $53.1484 \pm 1.1998,40.0525 \pm 0.8068,0.0037 \pm 0.0002$, $0.0224 \pm 0.0004$, and $0.0604 \pm 0.0009$ respectively. Meanwhile, Tawau (TW) shows the highest mean pollutant contribution of $\mathrm{CO}$ which is $1.0281 \pm 0.0096$. As a result, these descriptive statistics proved that PJ is the most polluted city in Malaysia.

Table 2. Descriptive statistics for air pollutants concentration in 2018

\begin{tabular}{cccccc}
\hline Pollutant & City & Mean $\pm \mathrm{SD}$ & Minimum & Median & Maximum \\
\hline & TW & $32.5598 \pm 0.6046$ & 10.243 & 31.17 & 132.709 \\
$\mathrm{PM}_{10}$ & AS & $37.7638 \pm 1.0634$ & 11.703 & 33.121 & 229.313 \\
& PJ & $53.1484 \pm 1.1998$ & 21.131 & 48.471 & 221.062 \\
\hline & TW & $19.6231 \pm 0.4820$ & 7.245 & 18.143 & 116.322 \\
$\mathrm{PM}_{2.5}$ & AS & $29.1181 \pm 0.9845$ & 8.468 & 24.303 & 209.692 \\
& PJ & $40.0525 \pm 0.8068$ & 12.922 & 37.519 & 190.229 \\
\hline & TW & $0.00110 \pm 0.00001$ & 0.0007 & 0.0011 & 0.0021 \\
$\mathrm{SO}_{2}$ & AS & $0.0013 \pm 0.00002$ & 0.0004 & 0.0012 & 0.0035 \\
& PJ & $0.0037 \pm 0.0002$ & 0.0005 & 0.003 & 0.0164 \\
\hline & TW & $0.01458 \pm 0.0002$ & 0.0049 & 0.0144 & 0.0324 \\
$\mathrm{NO}_{2}$ & AS & $0.01330 \pm 0.0002$ & 0.0051 & 0.0128 & 0.0321 \\
& PJ & $0.0224 \pm 0.0004$ & 0.0053 & 0.0218 & 0.0508 \\
\hline & TW & $0.0246 \pm 0.0003$ & 0.008 & 0.0243 & 0.0463 \\
$\mathrm{O}_{3}$ & AS & $0.0405 \pm 0.0007$ & 0.0145 & 0.0388 & 0.0897 \\
& PJ & $0.0604 \pm 0.0009$ & 0.0112 & 0.0601 & 0.122 \\
\hline & TW & $1.0281 \pm 0.0096$ & 0.519 & 1.008 & 1.681 \\
& AS & $0.9436 \pm 0.0126$ & 0.472 & 0.920 & 2.553 \\
& & $0.9835 \pm 0.0113$ & 0.49 & 0.968 & 2.033 \\
\hline
\end{tabular}


According to the entropy method, the determination of objective criteria weights is based on the measurement of the unforeseeable information contained in each criterion of the decision matrix. The calculation of entropy directly generates a set of weights for a given criteria based on mutual contrast of individual criteria values of variants for each criterion and also for all the criteria at the same time. Table 3 shows the air pollutants weights by using Shannon entropy method. The results also indicate the rank for each of pollutant towards its contribution to air pollution. From the result in Table 3, $\mathrm{SO}_{2}$, is at the highest rank of contribution to the air pollution in the PJ city with $48.16 \%$ of the air pollutants' weight. As mentioned by Manisalidis, Stavropoulou, Stavropoulos and Bezirtzoglou [21] $\mathrm{SO}_{2}$ is a harmful gas emitted mainly from fossil fuel consumption or industrial activities. Thus this is proven since $\mathrm{PJ}$ is one main urban city that has heavy traffics and many industries which directly emitted higher amount of $\mathrm{SO}_{2}$. The higher concentration of $\mathrm{SO}_{2}$ in the atmosphere can increase the number of hospital admissions especially of those who are easily affected such as children and elderly people. This air pollutant is able to trigger the onset of acute myocardial infarction and increase hospitalization for cardiovascular disease[22]. However, the $\mathrm{CO}$ is at the lowest rank in PJ city with only 0.04894 weight value or less that $5 \%$ contribution to air pollution in PJ city.

Meanwhile, both TW and AS ranked the particulate matter with aerodynamic diameter less than 2.5 micrometre at the first position with $36.31 \%$ and $31.79 \%$ respectively. The higher concentration of $P M_{2.5}$ at TW and AS maybe due to the construction sites activities, unpaved roads and also complex reaction of chemicals. This could be a result of TW as the third urban area in Sabah and AS is the capital city of state of Kedah where lot of construction takes place.

However, from the overall analysis, the highest rank pollutant or pollutant with the highest weight is particulate matter with aerodynamic diameter less than 2.5 micrometre $\left(P M_{2.5}\right)$ as shown in Table 4. The exposure of this particulate matter is very dangerous because it is proven that it can increase the risk of cardiovascular diseases, morbidity and mortality due to the increase of cardiovascular disease for people who live in area with higher long-term average particulate matter [23]. Department of Statistics Malaysia has reported that ischaemic heart disease is one cardiovascular disease that remained as the main causes of death in Malaysia, with $15.0 \%$ of the 109,164 medically certified death in 2019 [24]. The ischaemic disease is related to the blood supply restriction to human's tissue in any particular part of the body.

The higher concentration of the pollutant in the atmosphere will bring harmful effects to the human life in particular $P M_{2.5}$ and $P M_{10}$, where this fine particles can lodge deeply in the lungs and more likely to be retained[25]. The results of pollutants' weights based on the Shannon entropy method as in Table 4 show that the finest particle, the PM2.5 is ranked at first position for two cites out of the three cities, while the $P M_{10}$ is ranked second for all of the three cities. This shows that $P M_{2.5}$ is the most hazardous pollutant to both cities, TW and AS, while PM10 is the second most hazardous pollutant to all three cities under study. These results indicate that level of hazardous in both cities are not in a good situation since these pollutants can disturb the airways or respiratory system, trigged lung cancer and worst the heart malfunction which will lead to death. Yet, the highest concentration of Sulphur Dioxide associated with particulate matter is very dangerous to human health due to its harmful effects. The relationship between human health and concentration of sulphur dioxide in the atmosphere is very difficult to decipher especially with compounding factor such as particulate matter that presents simultaneously $[26,27]$.

Table 3. Results of air pollutants weights using entropy method

\begin{tabular}{|c|c|c|c|}
\hline Pollutant & City & Weight & Rank \\
\hline \multirow{3}{*}{$\mathrm{PM}_{10}$} & TW & 0.23547 & 2 \\
\hline & $\mathrm{AS}$ & 0.23042 & 2 \\
\hline & PJ & 0.14807 & 2 \\
\hline \multirow{3}{*}{$\mathrm{PM}_{2.5}$} & TW & 0.36307 & 1 \\
\hline & $\mathrm{AS}$ & 0.31791 & 1 \\
\hline & PJ & 0.12832 & 3 \\
\hline \multirow{3}{*}{$\mathrm{SO}_{2}$} & TW & 0.06062 & 6 \\
\hline & $\mathrm{AS}$ & 0.16966 & 3 \\
\hline & PJ & 0.48164 & 1 \\
\hline \multirow{3}{*}{$\mathrm{NO}_{2}$} & TW & 0.14724 & 3 \\
\hline & $\mathrm{AS}$ & 0.10493 & 5 \\
\hline & $\mathrm{PJ}$ & 0.09929 & 4 \\
\hline \multirow{3}{*}{$\mathrm{O}_{3}$} & TW & 0.12668 & 4 \\
\hline & $\mathrm{AS}$ & 0.11586 & 4 \\
\hline & PJ & 0.09373 & 5 \\
\hline \multirow{3}{*}{$\mathrm{CO}$} & TW & 0.06691 & 5 \\
\hline & AS & 0.06121 & 6 \\
\hline & PJ & 0.04894 & 6 \\
\hline
\end{tabular}

In order to obtain the overall ranking as shown in Table 4 , the average rank method is applied in the calculation. The average rank method is simply the simple arithmetic average of ranks of each pollutant for all three cities. In this case, the sum of the rank for each pollutant is divided by three and the average values were sorted in increasing order to get the new rank.

Table 4. Overall ranking of the pollutants

\begin{tabular}{ccccccc}
\hline Pollutant & $\mathrm{PM}_{10}$ & $\mathrm{PM}_{2.5}$ & $\mathrm{SO}_{2}$ & $\mathrm{NO}_{2}$ & $\mathrm{O}_{3}$ & $\mathrm{CO}$ \\
\hline Rank & 2 & 1 & 3 & 4 & 5 & 6 \\
\hline
\end{tabular}

Based on Table 4, $P M_{2.5}$ is ranked at the first position, which means that it is the most hazardous air pollutant, 
$P M_{10}$ is the second most hazardous air pollutant, and $\mathrm{CO}$ is at the sixth position. The analysis found $\mathrm{CO}$ as the lowest ranked pollutant which means that it gives the least contribution to air pollution incidence.

\section{Conclusions}

This study focuses on the objective weights of pollutants which were determined by using the Shannon Entropy method. These objective weights of the air pollutants represent the level of hazardous that these air pollutants can bring to humans' lives. The results show that particulate matter with aerodynamic diameter less than 2.5 micrometres and particulate matter with aerodynamic diameter less than 10 micrometres are at the most and second most hazardous pollutants respectively that contribute to the air pollution especially for the three selected cities. Besides, the principal death in Malaysia is caused by the ischaemic heart disease, one of the cardiovascular diseases where the patients' airways are disturbed by the fine particulate matter in the atmosphere. The effect of these two particulate matters is said to be more serious since sulphur dioxide that associated with both particulate matters are difficult to breakdown and bring harmful effects in human life as compared to the other air pollutants.

The results of this study will be used in the construction of an improved API after the subjective weights of the air pollutants are obtained. The determination of subjective weights requires experts to give opinion regarding the level of hazardous of the pollutants. Combination of both objective and subjective weights of the pollutants in API will ensure more accurate and informative API reading. The accurate API reading will give benefits to the government in particular the Ministry of Health in order to tackle the air pollution problems. It will help the government to take the correct intervention or prevention action corresponding to the air pollution situation. Lastly, this study is important to the community, where it will give the accurate information of air quality status and the community can adjust their daily activities accordingly.

\section{Acknowledgement}

This project is funded by Ministry of Higher Education of Malaysia under the Fundamental Research Grant Scheme (FRGS 2019-1) with Application ID: 281098-329674 and Reference Code: FRGS/1/2019/STG06/UUM/02/3. The data for this project is provided by Air Quality Division of the Department of Environmental of Malaysia.

\section{REFERENCES}

[1] F. Sweeny and R. Mitchell, Ecology, Environment and Pollution, Waltham Abbey Essex: ED-Tech Press, 2019.

[2] C. D. Koolen and G. Rothenberg, "Air Pollution in Europe," ChemSusChem, vol. 12, pp. 164-172, 2018.

[3] K. K. Mokoena, C. J. Ethan, Y. Yu, K. Shale and F. Liu, "Ambient air pollution and respiratory mortality in Xi'an, China: a time-series analysis," Respiratory Research, vol. 20, no. 139, pp. 1-9, 2019.

[4] K. Balakrishnan, S. Dey, T. Gupta, R. S. Dhaliwal, M. Brauer, A. J. Cohen, J. D. Stanaway and G. Beig, "The impact of air pollution on deaths, disease burden, and life expectancy across the states of India: the Global Burden of Disease Study 2017," The Lancet Planetary Health, vol. 3, no. 1, pp. 26-39, 2019.

[5] M. Schenker, "Occupational lung diseases in the industrializing and industrialized world due to modern industries and modern pollutants," Tubercle and Lung Disease, pp. 73(1), 27-32, 1992.

[6] A. Purwadi, S. Suhandi and U. Enggarsasi, "Urban air pollution control caused by exhaust gas emissions in developing cities in public policy law perspective," International Journal of Energy Economics and Policy, pp. 10(1), 31-36, 2020.

[7] G. McCarron, "Air pollution and human health hazards: a compilation of air toxins acknowledge by gas industry in Queensland's darling Downs," International Journal of Environmental Studies, pp. 75(1), 171-185, 2018.

[8] "World Health Organization (WHO)," 2 May 2018. [Online]. Available: https://www.who.int/westernpacific/news/detail /02-05-2018-one-third-of-global-air-pollution-deaths-in-asi a-pacific.

[9] M. A. B. A. Tajudin, M. F. Khan, W. R. W. Mahiyuddin, R. Hod, M. T. Latif, A. H. Hamid, S. A. Rahman and M. Sahani, "Risk of concentrations of major air pollutants on the prevalence of cardiovascular and respiratory diseases in urbanized area of Kuala Lumpur, Malaysia," Ecotoxicol Environment Saf, vol. 171, pp. 290-300, 2019.

[10] Department of Environment (DOE), "Official Portal of Department of Environment," 2020. [Online]. Available: https://www.doe.gov.my/portalv1/en/info-umum/english-ai r-pollution-index-api/100.

[11] R. Afroz, M. N. Hassan and N. A. Ibrahim, "Review of air pollution and health impacts in Malaysia," Envirnmental Research, pp. 92(2003), 71-77, 2002.

[12] Y. Alyousifi, M. Othman, R. Sokkalingam, I. Faye and P. C. L. Silva , "Predicting Daily Air Pollution Index Based on Fuzzy Time Series Markov Chain Model," Symmetry, vol. 12, no. 293, pp. 1-18, 2020.

[13] M. M. Kasim, "Aggregation of criteria weights for multi-person decision making with equal or different credibilty," Journal of Quality Measurement and Analysis, pp. 14(1), 1-7, 2018.

[14] E. U. Choo, B. Schoner and W. C. Wedley, "Interpretation of criteria weights in multicriteria decision making," Computers \& Industrial Engineering, pp. 527-541, 1999. 
[15] X. Li, K. Wang, L. Liu, J. Xin, H. Yang and C. Gao, "Application of the Entropy Weight and TOPSIS Method in Safety Evaluation of Coal Mines," Procedia Engineering, pp. 2085-2091, 2011.

[16] Q. Zhang, W. Xu and J. Zhang, "Method for Determining the Weight of Functional Objectives on Manufacturing System," The Scientific World Journal, pp. 1-10, 2014.

[17] M. N. H. Desa, A. A. Jemain and M. M. Kasim, "Construction of a composite hospital admission index in Klang Valley, Malaysia by considering the aggregated weights of criteria," Sains Malaysiana, pp. 44(2), 239-247, 2015.

[18] "IQAir," 2020. [Online]. Available: https://www/iqair.com/ us/malaysia.

[19] C. L. Hwang and K. Yoon, Multiple attribute decision making: Methods and applications, Springer, 1981.

[20] M. D. Vujicic, M. Z. Papic and M. D. Blagojevic, "Comparative Analysis of Objective Techniques for Criteria Weighing in Two MCDM Methods on Example of an Air Conditioner Selection," Tehnika- Menadzment, pp. 422-429, 2017.

[21] I. Manisalidis, E. Stavropoulou, A. Stavropoulos and B. Eugenia, "Environmental and Health Impacts of Air Pollution: A review," Frontiers in Public Health, vol. 8, no. 14, pp. 1-39, 2019.

[22] X.-Q. Jiang, X.-D. Mei and D. Feng, "Air pollution and chronic airway diseases: what should people know and do?," Journal of Thoracic Disease , vol. 8, no. 1, pp. 31-40,
2015.

[23] R. D. Brook, S. Rajagopalan,. C. A. Pope, J. R. Brook, A. Bhatnagar, A. V. Diez-Roux, F. Holguin, Y. Hong, R. V. Luepker, M. A. Mittleman, . A. Peters, D. Siscovick, S. C. Smith, L. Whitsel and J. D. Kaufman, "Particulate Matter Air Pollution and Cardiovascular Disease," circulation journal of the american heart assosiation, vol. 121, pp. 2331-2378, 2015.

[24] "Statistics on Causes of Death, Malaysia, 2020," Official Portal Department of Statistics Malaysia, 26 November 2020. [Online]. Available:https://www.dosm.gov.my/v1/in dex.php? $\mathrm{r}=$ column/cthemeByCat\&cat $=401 \&$ bul_id=QTU5 T0dKQ1g4MHYxd3ZpMzhEMzdRdz09\&menu_id=L0ph eU43NWJwRWVSZk1WdzQ4TlhUUT09. [Accessed 26 May 2021].

[25] G. B. Hamra, N. Guha, A. Cohen, F. Laden, O. R. Nielsen, J. M. Samet, P. Vineis, F. Forastiere, P. Saldiva, T. Yorifuji and D. Loomis, "Outdoor Particulate Matter Exposure and Lung Cancer: A Systematic Review an Meta-Analysis," Environmental Health Perspectives, pp. 906-911, 2015.

[26] B. G. Miller, "The effect of coal usage on human health and the environment," in Clean Coal Engineering Technology, ELSEVIER, 2011, pp. 85-132.

[27] X. Pan, "Sulfur oxides: Sources, exposures and health effects," in Encyclopedia of Environmental Health, ELSEVIER, 2011, pp. 290-296.

[28] A. Bradford, "Livescience," 28 February 2018. [Online]. Available: https://www.livescience.com/22728-pollution-f acts.html. 